\title{
Early development of the facial nerve in human embryos at stages 13-15
}

\author{
M. Weglowski, W. Woźniak, A. Piotrowski, M. Bruska, J. Weglowska, \\ J. Sobański, M. Grzymisławska, J. Łupicka \\ Department of Anatomy, Poznan University of Medical Sciences, Poznan, Poland
}

[Received 6 March 2015; Accepted 17 April 2015]

\begin{abstract}
Study was made on 16 human embryos at developmental stages 13-15 (fifth week). The facial nerve was traced on serial sections made in three planes (sagittal, frontal and horizontal) and stained with routine histological methods and impregnated with silver. In embryos at stage 13 the facial ganglion forms a complex structure with the vestibulocochlear ganglion. It is of fusiform shape in contact with epipharyngeal placode and is located anteriorly and ventrally to the vestibulocochlear ganglion. In embryos at stage 14 the facial ganglion separates from the vestibular and cochlear ganglia and the chorda tympani as the first branch appears. During stage 15 the main trunk of the facial nerve elongates and the greater petrosal nerve originates at the level of the facial ganglion and above the origin of the chorda tympani. (Folia Morphol 2015; 74, 2: 252-257)
\end{abstract}

Key words: human embryonic period, nervous system, facial nerve

\section{INTRODUCTION}

The facial nerve is a second pharyngeal arch nerve and it is a complex structure considering: 1) the types of fibres, 2) the range of innervation, 3) the intracranial, intratemporal, and extracranial parts, 4) the pattern of ramifications, and 5) the range of innervation. The facial nerve contains somatic efferent (motor) fibres, visceral efferent (parasympathetic) fibres, general somatic sensory fibres, and special visceral sensory (taste) fibres $[9,13]$.

Buskirk [9] estimated that $58 \%$ of the fibres of the facial nerve in man are motor, $24 \%$ are autonomic, and $18 \%$ are sensory.

The intracranial part of the facial nerve extends from its exit at the posterior border of the pons in the cerebellopontine angle to the internal auditory meatus. From the brain stem the nerve emerges as two roots: motor and sensory. The motor root is larger. The sensory root, also called intermediate nerve, contains sensory and parasympathetic fibres [1, 8 ,
$21,33]$. The sensory fibres of the intermediate nerve comprise the greater part of this nerve.

Within the internal auditory meatus the intermediate nerve and motor root unite and form a single trunk which enters the facial canal.

Despite many studies on the intratemporal (intraosseous) part of the facial nerve, there are still controversies as to the topography of this nerve to the developing internal and middle ear $[2,14,17$, 34-36, 39].

Gasser [14-16] and Sataloff [34, 35] described the development of the facial nerve in embryos classified according to the length and expressed the embryonic age in weeks. Gerhardt [17] paid attention to explain caudal deviation of the facial nerve in relation to facial ganglion and developmental malposition of the facial nerve.

Recently O'Rahilly and Müller [27, 28] studied the development of the cranial nerves in human embryos. They were concerned mainly with the neuronal

Address for correspondence: Prof. M. Bruska. Department of Anatomy, Poznan University of Medical Sciences, ul. Święcickiego 6, 60-781 Poznań, Poland, tel: +48 6185465 64, fax: +48 6185465 68, e-mail: mbruska@ump.edu.pl 
Table 1. Crown-rump (CR) length, developmental stage and postovulatory days of investigated embryos

\begin{tabular}{lcccc}
\hline Catalogue no. & CR length [mm] & Developmental stage & Age [days] & Plane of section \\
\hline B171 & 4.0 & 13 & 32 & Frontal \\
B202 & 4.5 & 13 & 32 & Horizontal \\
B213 & 4.5 & 13 & 32 & Frontal \\
B207 & 6.0 & 13 & 32 & Sagittal \\
B194 & 6.0 & 13 & 32 & Horizontal \\
B195 & 5.5 & 14 & 33 & Sagittal \\
A13 & 7.0 & 14 & 33 & Sagittal \\
B186 & 7.5 & 14 & Horizontal \\
A19 & 7.0 & 14 & Frontal \\
As21 & 7.5 & 14 & 33 & Frontal \\
PJK5 & 8.0 & 15 & 33 & Sagittal \\
B75 & 8.0 & 15 & 35 & Horizontal \\
PJK20 & 9.0 & 35 & Horizontal \\
PJK18 & 15 & 35 & Frontal \\
B175 & 9.0 & 15 & 35 & Frontal \\
B69 & 9.0 & 15 & 35 & Horizontal \\
\hline
\end{tabular}

migration, formation of the nuclei in the brain stem and sequence of appearance of the cranial nerves.

Many conflicting reports exist on the early development of the facial nerve, particularly considering relationship between the facial and vestibulocochlear ganglia and the time of appearance of the first branches [3, 14-16, 34, 35].

During the first 8 weeks of development, more than $90 \%$ of the named structures appear. It is important to determine exact time of development of structures and establish events in the formation of body systems.

Descriptive embryology based on standard serial histological sections with graphic reconstructions is still valid tool to pursue human development. However, it is important in this study to determine the age of investigated specimens, particularly during the embryonic period.

The present study was performed on serial sections and graphic reconstructions of staged human embryos aged 5 weeks.

\section{MATERIALS AND METHODS}

The study was performed on 16 human embryos at developmental stages 13-15 (postovulatory days between 32 and 36, Table 1). Embryos from the collection of the Department of Anatomy, Poznan University of Medical Sciences, were staged according to international Carnegie staging $[22,24,30]$.
Serial sections of embryos made in three planes (sagittal, horizontal, and frontal), were stained according to routine histological methods and impregnated with silver. Graphic reconstructions were made at least two at each stage. The general features of various structures (neuromeres, ganglia of the cranial nerves) were determined.

\section{RESULTS}

Embryos at stage 13 (32 postovulatory days)

Both neuropores of the neural tube are closed and its canal, forming the future ventricular system, is separated from the amniotic cavity. All three layers in the wall of the neural tube are distinguishable. The motor nuclei of the cranial nerves separate from the common efferent tract. The sensory nuclei develop in the common afferent tract. The motor nucleus of the facial nerve is medial to the abducent nucleus. In the secondary brain vesicles, the neuromeres are indicated. Ganglia of the cranial nerves and their relations to the pharyngeal arches are visible (Fig. 1). The external surfaces of the rhombencephalic neuromeres are well indicated. All three branches of the trigeminal ganglion are discerned. The otic vesicle is separated from the surface and its dorsal part, as the primordium of the endolymphatic appendage, is seen. The facial ganglion forms a common complex with the vestibulocochlear ganglion (Fig. 2). It pre- 


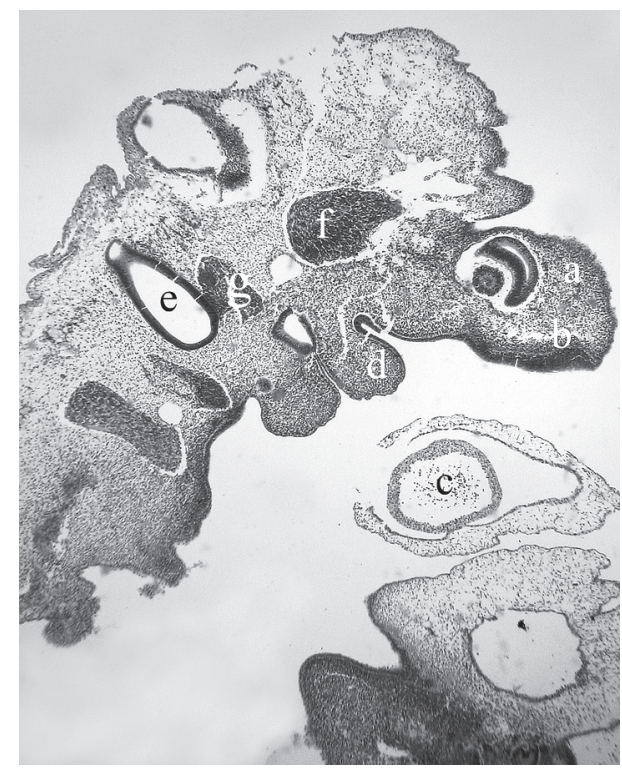

Figure 1. Sagittal section of human embryo at stage 13. Cresyl violet, $\times 40$; $a$ - frontonasal eminence; $b$ - olfactory crest; $c$ - heart; $d$ - first pharyngeal arch; $e$ - otic vesicle; $f$ trigeminal ganglion; $\mathrm{g}$ - facial ganglion.

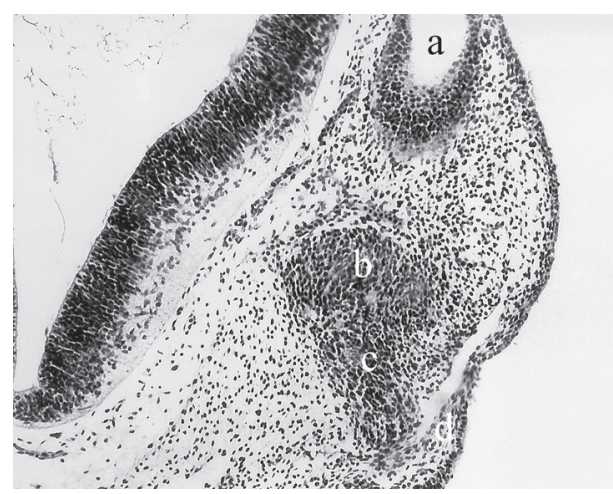

Figure 2. Frontal section of human embryo at stage 13. Cresyl violet, $\times 100$; $a-$ otic vesicle; $b-$ vestibulocochlear ganglion; $c$ - facial ganglion; $d$ - epipharyngeal placode.

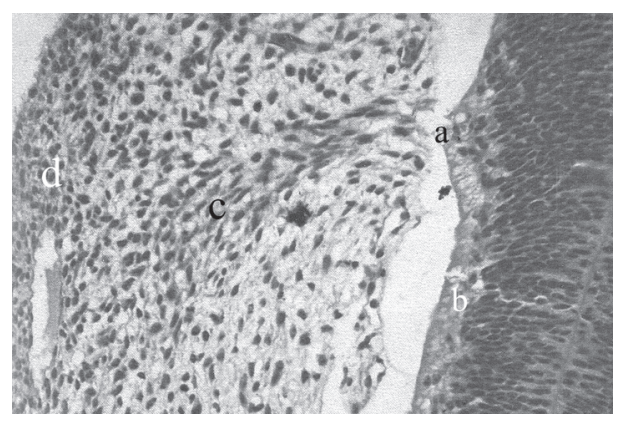

Figure 3. Sagittal section of human embryo at stage 13. Cresyl violet, $\times 400$; $a$ - roots of the facial nerve; $b$ - rhombencephaIon; $\mathrm{c}$ - facial ganglion; $\mathrm{d}$ - epipharyngeal placode of the second pharyngeal arch.

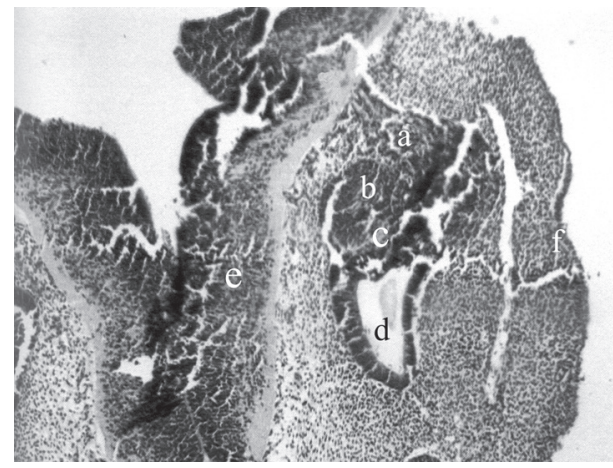

Figure 4. Frontal section of human embryo at stage 13. Haematoxylin \& eosin, $\times 150$; $a$ - facial ganglion; $b-$ cochlear ganglion; $\mathrm{c}$ - vestibular ganglion; $\mathrm{d}$ - otic vesicle; e — rhombencephalon; $\mathrm{f}$ - epipharyngeal placode.

sents a fusiform structure with cells arranged in rows and is traversed through nerve fibres (Fig. 3). The ganglion is in the contact with epipharyngeal placode of the second pharyngeal arch and is located ventrally and anteriorly to the vestibulocochlear ganglion at the level of the rhombencephalic neuromere 4 . The facial neural crest is still visible.

\section{Embryos at stage 14 (33 postovulatory days)}

Future cerebral hemispheres are delineated and the telencephalon medium is separated from the diencephalon through the torus hemisphericus. Within the brain, 16 neuromeres are well defined. The epipharyngeal placode and neural crest contributing cells to the trigeminal and facial ganglia are present. All ganglia forming facial-vestibulocochlear complex are distinguishable (Fig. 4). The nuclei of the cranial nerves in the brain stem are well formed. The mesencephalic and spinal trigeminal tracts develop. From the trunk of the facial nerve originates the chorda tympani as the first branch of this nerve (Fig. 5). It passes anteriorly whereas the main trunk of the facial nerve courses ventrally and posteriorly in the direction to the second pharyngeal arch.

\section{Embryos at stage 15 (35 postovulatory days)}

The cerebral hemispheres are well developed. The diencephalon is divided into future five zones. The motor and sensory nuclei of the cranial nerves are distinct and several tracts in the brain stem appear. The motor nucleus of the facial nerve lies medially to the abducent nucleus in the future dorsomedial nuclear column. The intracranial part of the facial nerve elongates. At the level of the facial ganglion 


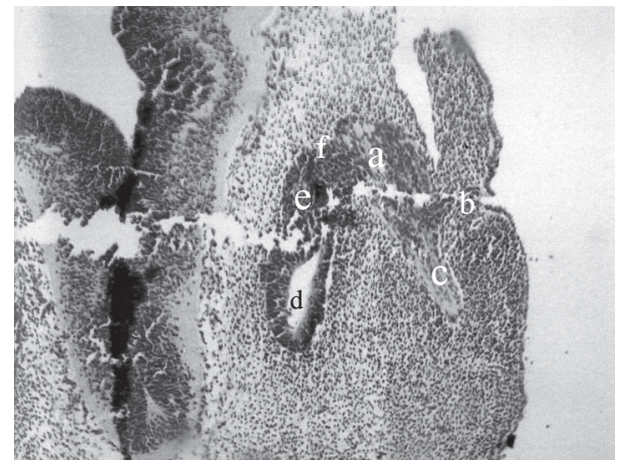

Figure 5. Frontal section of human embryo at stage 14. Bodian's protargol, $\times 100$; $a-$ facial ganglion; $b-$ chorda tympani; $c-$ trunk of facial nerve; $d$ - otic vesicle; $\mathrm{e}$ - vestibular ganglion; $\mathrm{f}-$ cochlear ganglion.

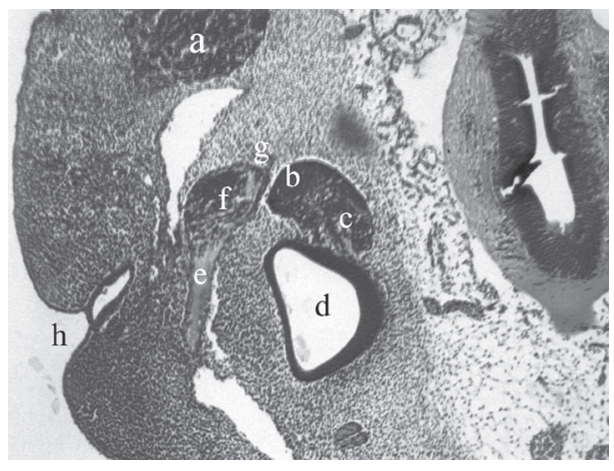

Figure 6. Horizontal section of human embryo at stage 15. Bodian's protargol, $\times 100$; $a$ - trigeminal ganglion; $b-$ cochlear ganglion; $c$ - vestibular ganglion; $d$ - otic vesicle; e - trunk of facial nerve; $f$ - facial ganglion; $g$ - greater petrosal nerve; $\mathrm{h}$ - external auditory meatus.

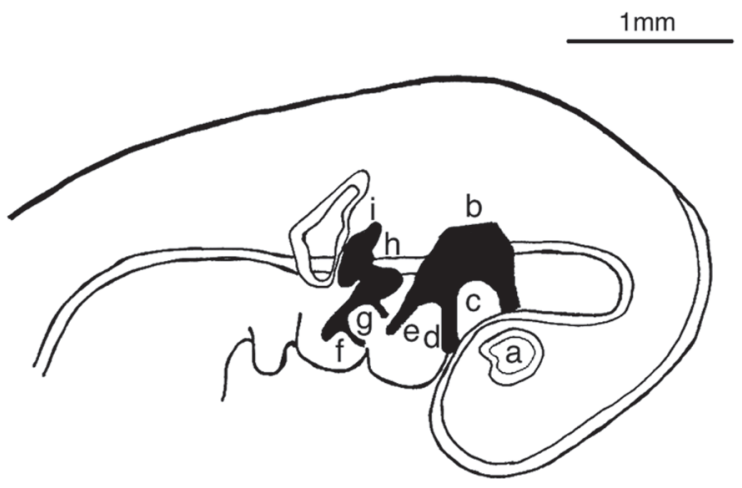

Figure 7. Reconstruction of brain in human embryo at stage 15; $a$ - eye; $b$ - trigeminal ganglion; $c$ - ophthalmic nerve; $d$ maxillary nerve; $\mathrm{e}-$ mandibular nerve; $\mathrm{f}$ - chorda tympani; $\mathrm{g}$ - greater petrosal nerve; $\mathrm{h}$ - facial ganglion; $\mathrm{i}$ - cochlear and vestibular ganglia. arises greater petrosal nerve. It is directed anteriorly (Figs. 6, 7). Ventrally to the greater petrosal nerve arises the chorda tympani which also passes anteriorly. The main trunk of the facial nerve forms a slide arch bent anteriorly. This segment may be considered as the primordium of the horizontal part of the nerve.

\section{DISCUSSION}

During the investigated period of embryonic development (fifth week), many important features in the brain appear. These include: 1) closure of neuropores and separation of the neural tube from amniotic cavity, 2) appearance of the neuromeres and subdivision of the neural crest, 3) presence of the five chief parts of the brain, 4) formation of the cerebral hemispheres, 5) formation of the nuclei of the cranial nerves in the brain stem, 6) development of the cranial nerves ganglia, and 7) appearance of the branches of the cranial nerves. In humans, only two sites of fusion of the neural folds and two neuropores are found and the closure of the anterior neuropore is bidirectional $[25,26]$. It proceeds simultaneously from a dorsal lip (midbrain - diencephalon border) and from a ventral lip (telencephalic region).

The cerebral hemispheres, which was also confirmed in the present study, are identifiable at stage 14 and are well marked during stage 15 [19, 27, 29].

They are marked from the telencephalon medium by the di-telencephalic sulcus externally and by the torus hemisphericus internally. The longitudinal fissure between two hemispheres is more evident. The future interventricular foramina between lateral cerebral hemispheres and the telencephalon medium narrow.

Appearance of the main parts of the brain and transverse subdivisions, perpendicular to the longitudinal axis of the brain result in formation of the neuromeres. The neuromeres are very important in location of developing nuclei and ganglia of the cranial nerves and their relationship to domain of gene expression $[18,20,24,27]$.

In the performed study, in human embryos at stage 15 all 16 neuromeres were present. In the hindbrain the neuromeres named rhombomeres function as restriction boundaries of cellular movements $[18,20]$.

The motor nuclei of the cranial nerves differentiate during the fifth week from the efferent motor column $[4-6,12,27,31,32,37]$. The sensory nuclei of the cranial nerves develop in the common afferent tract $[6,11,20,28]$. 
The motor nucleus of the facial nerve in all investigated stages is medially to the abducent nucleus in the future dorsomedial nuclear column.

The important structure during the development of the nervous system is the neural crest which gives rise to variety of derivatives including the spinal and cranial ganglia [28]. In human embryos, the neural crest is indicated first at stage 9 in mesencephalic neuromere. The facial and vestibulocochlear ganglia develop from the facial and otic crest opposite neuromere 4 and 5 . The trigeminal, facial, glossopharyngeal and vagal ganglia develop from the neural crest and epipharyngeal placode $[10,11,38]$ which are a part of the ectodermal ring and appear at stage 12 [23].

The epipharyngeal placode over the second pharyngeal arch were observed in embryos at stage 13.

In the present study it was found that in embryos at stage 13 the facial ganglia form complex structure with the vestibulocochlear ganglion. This was also found in the previous observations $[7,40]$.

Sataloff $[34,35]$ found facioacoustic primordium in embryos of 3 weeks and identified the chorda tympani in embryos of $4.8 \mathrm{~mm}$ long which corresponds to stage 13. He also observed extracranial branches of the facial nerve in embryos of 5 weeks. This is not in accord with results of the present study and may result from not precise determination of the embryonic age.

Gasser $[14,16]$ who determined the age of embryos according to length presented the development of the facial nerve in 4 stages. During stage I (embryos 4.2-6.5 $\mathrm{mm}$ ) the ganglion forms common primordium with the vestibulocochlear ganglion and the chorda tympani arises. In the stage II (embryos 8.0-20.0 mm) appears the greater petrosal nerve which joins the deep petrosal nerve. In his another paper Gasser [15] found the chorda tympani in embryos at stage 15 . It has to be stressed that in embryos at stage 13 the facial nerve gives no branches.

\section{CONCLUSIONS}

The present study, based on international Carnegie staging showed that in embryos aged 5 weeks the facial ganglion separates from the vestibulocochlear ganglia and 2 branches of the nerve appear: the chorda tympani at stage 14 and the greater petrosal nerve at stages 15 .

\section{REFERENCES}

1. Alfieri A, Strauss Ch, Prell J, Pesche E (2010) History of the nervus intermedius of Wrisberg. Ann Anat, 192: 139-144.

2. Anson B (1965) Die Embryologie und Anatomie des Facialiskanals und des Facialisnerven. Ohren Nasen Kehlkopfheilk, 184: 269-284.

3. Arnold WH, Kleiner A (2004) 3D reconstruction of the cardiovascular and central nervous system of a human embryo Carnegie-stage 15 (case report). Ann Anat, 186: 133-139.

4. Bruska M, Woźniak W (1991) The development of the main sensory nucleus of the trigeminal nerve in human embryos. Folia Morphol, 50: 127-138.

5. Bruska M, Woźniak W (1992) Early develompent of the mesencephalic nucleus of the trigeminal nerve in human embryos (stages 14 and 15). Folia Morphol, 51: 31-42.

6. Bruska M, Markowski M, Szyszka-Mróz J, Ulatowska-Błaszyk K, Woźniak W (1990) Segmental pattern and nuclei in the human embryonic brain at stage 13 . Folia Morphol, 57: 321-330.

7. Bruska M, Ulatowska-Błaszyk K, Węgłowski M, Woźniak W, Piotrowski A (2009) Differentiation of the facial-vestibulocochlear ganglionic complex in human embryos of developmental stages 13-15. Folia Morphol, 68: 167-173.

8. Bruyn GW (1984) Nervus intermedius neuralgia (Hunt). Cephalalgia, 4: 71-78.

9. Buskirk C van (1945) The seventh nerve complex. J Comp Neurol, 82: 303-333.

10. D'Amico-Martel A, Noden DM (1983) Contributions of placodal and neural crest cells to cranial peripheral ganglia. Am J Anat, 166: 445-468.

11. Davies AM, Lumdsen A (1990) Ontogeny of the somatosensory system: origins and early development of primary sensory neurons. Annu Rev Neurosci, 13: 61-73.

12. Fabiani $F$ (1957) L'ontogenesi del nucleo motore del nervo facciale nell'uomo. Riv Patol Nerv Ment, 78: 421-471.

13. Foley JO (1960) Quantitative studies of the functional components of the facial nerve. Am J Anat, 107: 237-244.

14. Gasser RF (1967) The development of the facial nerve in man. Ann Otol Rhinol Laryngol, 76: 37-56.

15. Gasser RF (1970) The early development of the parotid gland around the facial nerve and its branches in man. Anat Rec, 167: 63-78.

16. Gasser RF, May M (1986) Embryonic development of the facial nerve. In Facial nerve. Thieme Inc, New York, 3-20.

17. Gerhardt HJ (1981) The intratemporal course of the facial nerve and its influences on the development of the ossicular chain. Acta Otolaryngol, 91: 567-573.

18. Keynes R, Lumsden A (1990) Segmentation and origin of regional diversity in the vertebrate central nervous system. Neuron, 2: 1-9.

19. Müller F, O'Rahilly R (1988) The first appearance of the future cerebral hemispheres in the human embryo at stage 14. Anat Embryol, 177: 203-224.

20. Müller F, O'Rahilly R (1997) The timing and sequence of appearance of neuromeres and their derivatives in staged human embryos. Acta Anat, 158: 83-99. 
21. Oh CS, Chung IH, Lee KS, Tanaka S (2003) Morphological study on the rootlets comprising the root of the intermediate nerve. Anat Sci Int, 78: 111-113.

22. O'Rahilly R, (1979) Early human development and the chief sources of information on staged human embryos. Eur J Obsted Gynecol Reprod Biol, 9: 273-280.

23. O'Rahilly R, Müller F (1985) The origin of the ectodermal ring in staged human embryos of the first 5 weeks. Acta Anat, 122: 145-157.

24. O'Rahilly R, Müller F (1987) Developmental stages in human embryos including a revision of Streerer's "Horizons" and a survey of Carnegie collection. Carnegie Institution of Washington. Washington, DC.

25. O'Rahilly R, Müller F (1989) Bidirectional closure of the rostral neuropore in the human embryo. Am J Anat, 184: 259-268.

26. O'Rahilly R, Müller F (2002) The two sites of fusion of the neural folds and the two neuropores in the human embryo. Teratology, 61: 382-384.

27. O'Rahilly R, Müller F (2007) The embryonic human brain. An atlas of developmental stages. 3rd Ed, Wiley-Liss, Hoboken, NJ.

28. O'Rahilly R, Müller F (2007) The development of the neural crest in human. J Anat, 211: 335-351.

29. O'Rahilly R, Müller F (2008) Significant features in the early prenatal development of the human brain. Ann Anat, 190: 105-118.

30. O'Rahilly R, Müller F (2010) Developmental stages in human embryos: revised and new measurements. Cells Tissues Organs, 192: 73-84.
31. Pearson AA (1946) The development of the motor nuclei of the facial nerve in man. J Comp Neurol, 85: 461-476.

32. Pearson AA (1947) The roots of the facial nerve in human embryos and fetuses. J Comp Neurol, 87: 139-159.

33. Rhoton jr AL, Kobayashi S, Hollinshead WH (1968) Nervus intermedius. J Neurosurg, 29: 609-618.

34. Sataloff RT (1990) Embryology of the facial nerve and its clinical applications. Laryngoscope, 100: 969-984.

35. Sataloff RT (1991) Embryology and anomalies of the facial nerve. Raven Press, New York.

36. Streeter GL (1907) On the development of the membranous labyrinth and the acoustic and facial nerves in the human embryo. Am J Anat, 6: 139-166.

37. Streeter GL (1908) The peripheral nervous system in the human embryo at the end of the first month $(10 \mathrm{~mm})$. Am J Anat, 8: 285-301.

38. Streit (2007) The preplacodal region: an ectodermal domain with multipotential przogenitors that contribute to sense organs and cranial sensory ganglia. Int J Dev Biol, 51: 447-461.

39. Volcher R (1963) Le systeme nerveux peripherique d'un embryon humain de $8 \mathrm{~mm}$. Arch Biol, 74: 95-127.

40. Woźniak W, Bruska M, Ulatowska-Błaszyk K, Skórzewska A (1993) The vestibulocochlear ganglion in human embryos at stage 13. Folia Morphol, 52: 92-107. 